Hernández-Hernández, Fernando.

Profesor Unidad Pedagogías Culturales, Facultad de Bellas Artes. Universidad de Barcelona.

\title{
Pensar los límites y relaciones entre la práctica artística y la investigación artística.
}

\author{
TIPO DE TRABAJO \\ Comunicación invitada.
}

PALABRAS CLAVE

Práctica artística, investigación artística, investigación basada en las artes, investigación con y sobre imágenes.

KEY WORDS

Artistic practice, artistic research, arts based research, reseach with and on images.

\section{RESUMEN}

Esta es una contribución a una mesa redonda. El texto se presenta desde la posicionalidad de la que habla, para luego esbozar algunas relaciones y diferencias entre las diferentes ontologías, epistemologías y metodologías desde las que se vinculan las nociones y praxis de investigación y artes.

\section{ABSTRACT}

This is a contribution to a round table on artistic research. This paper, started by making explicit my positionality on this issue, and explore some of the possible relations and differences between the notion and praxis on arts and research under diverse ontologies, epistemologies and methodologies.

\section{CONTENIDO}

El lugar desde el que me sitúo para pensar lo que se nos propone en la mesa de debate

Hace casi una década, escribí con otros colegas un informe, que fue publicado por el Ministerio de Educación y Ciencia, sobre la investigación en artes. Lo que allí traté, en el capítulo que escribí (Hernández, 2006), fue poner de manifiesto que se estaban produciendo una serie de cambios en la investigación en las Ciencias Humanas y Sociales que podían contribuir a pensar desde otras referencias la investigación en las artes. Estos cambios tenían lugar sobre todo, a partir del cuestionamiento del marco ontológico, epistemológico y político realista y la entrada de la perspectiva narrativa (hemos aprendido a ser y conocer a partir de relatos) que podía contribuir a pensar y plantear desde otros fundamentos y con otras posibilidades, la investigación en el campo de las artes. Con este bagaje me adentré en una experiencia que fue rica, por las posibilidades que me abrió -seguramente también para los estudiantes-, y que me llevó a introducir el relato de la experiencia en la investigación sobre la práctica musical. Con ello se expandía no sólo lo que era investigar en artes, más allá de la musicología, sino que se aproximaban enfoques relacionados con la investigación narrativa al ámbito de la música.

Estos fueron los antecedentes. Pero donde lo que estaba emergiendo y haciéndose visible más allá de nuestras fronteras se pudo hacer patente, tuvo lugar desde la oportunidad que representó diseñar los estudios del grado de Bellas Artes y la posibilidad de introducir nuevas asignaturas optativas. En los cuatro últimos años, junto a Rachel Fendler, he tenido la oportunidad de explorar las relaciones entre práctica artística, investigación basada en las artes e investigación artística. Lo hemos hecho, además de en el postgrado Artes y Educación, en el curso Investigación basada en las artes, del grado de Bellas Artes. Al ser una asignatura optativa, con pocos estudiantes que se acercan entre la curiosidad, la incertidumbre y las ganas de compartir una aventura del pensar e indagar 
juntos, nos ha permitido no sólo explorar y expandir lo que significa transitar entre la investigación creativa, la investigación artística y la investigación basada en las artes, sino desarrollar proyectos colectivos de investigación en torno, por ejemplo, "el papel del silencio en las clases de la universidad" o "lo que significa ser estudiante de bellas artes y trabajador precario en un contexto de capitalismo cognitivo". Lo que ha sucedido en los encuentros entre las 8 y las 10 de la mañana, nos ha permitido generar una serie de modos de pensar e investigar, que se han concretado en trabajos y acciones que hemos llevado, junto a los estudiantes, a publicaciones y congresos (Onses, Fendler, Hernández-Hernández, 2012; Fendler \& Hernández-Hernández, 2013; Dorrego et alt., 2015).

A raíz de ese interés organizamos en Barcelona en 2012, unas primeras jornadas sobre Investigación artística e investigación basada en las artes, que han tenido su continuidad en Granada y Oporto. Desde ellas se ha ido generando un corpus de aportaciones que permiten perfilar no sólo lo que fundamenta el cambio que se está generando en la investigación relacionada con las artes, sino en lo que las artes -los métodos artísticos- pueden aportar a la investigación social.

\section{Esbozar un mapa para explorar posibilidades}

Para situar cómo representamos la relación entre investigación y artes, me permito aportar algo que apuntamos en nuestros cursos de IBA como campo inicial desde el que establecer vínculos y diferencias.
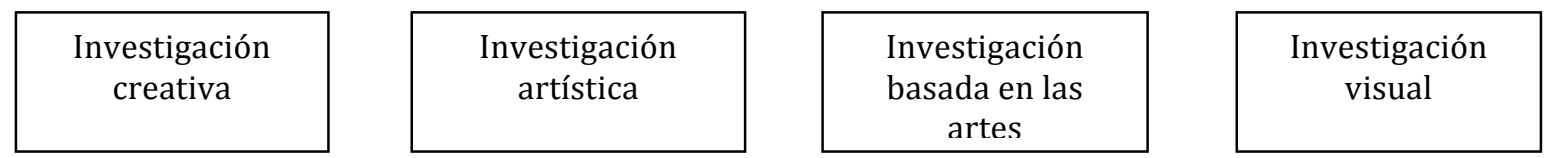

Esta diferencia, que si bien tiene una finalidad pedagógica y organizativa, reconoce relaciones y vínculos, y nos permite mostrar que no es lo mismo, ni se fundamenta en las mismas premisas y modos de relacionarse con el conocimiento, el sentido de investigación que tiene lugar cuando se plantea la pregunta 'qué voy a hacer' que cuando la cuestión de partida se refiere al 'qué quiero conocer'.

Nos permite también explorar que no tiene el mismo sentido el proceso de indagación (Eisner, 1998) que se vincula con la noción de investigación cuando se trata de preservar el secreto del proceso de producción de una obra artística, donde se valora como importante hacer público un resultado que habla por sí mismo, que cuando existe la preocupación de desvelar y hacer público el proceso, las fuentes, los modos de relación que se generan en torno al proceso de generar una obra artística. Convirtiendo en ocasiones este desvelamiento, en ocasiones en la producción artística.

Estas cuestiones las afronta con detalle Sullivan (2011) cuando explora la fundamentación de la práctica artística como investigación. Dos cuestiones nos parecen relevantes destacar de su análisis: el carácter aparadigmático de la investigación artística, y los modos de conocer que amplía -más allá de los que posibilitan las formas de investigación en las ciencias sociales y experimentales- la investigación desde la práctica artística.

También apuntamos que no tiene el mismo el sentido epistemológico usar las imágenes en la investigación desde, por ejemplo, la sociología o la etnografía visual, que desde un proyecto de fotoperiodismo, de documentación de un proceso de aprendizaje que de un proyecto artístico (Siegesmund \& Freedman, 2013).

También ilustramos que no es lo mismo utilizar la fotografía o el vídeo como práctica de pedagogía artística, que para expandir el sentido de la indagación a partir de plantear una pregunta de investigación (qué queremos conocer) y luego generar evidencias que permitan su puesta en relación como modo de análisis e interpretación que posibilite expandir las experiencias de conocer.

En Fendler y Hernández-Hernández (2013) ya presentamos lo que caracterizaba, relacionaba y diferenciaba las tres primeras de estas modalidades, señalando que nuestro punto de interés no iba tanto por la investigación creativa (que consideramos que es la que se aborda de manera preferente en los talleres de la facultad y en el estudio de muchos artistas y que establece un sinónimo que cuestionamos entre investigación artística y práctica artística), sino por las otras modalidades de investigación. Algunas de las tesis doctorales que se han finalizado recientemente en el programa en Artes y Educación tratan de comprender algunos de estos sentidos de la investigación artística (Calderón, 2014) o el papel de la documentación visual como proceso de investigación (Abakerli Baptista, 2014).

\section{Entre la investigación y la indagación}

La segunda distinción tiene que ver con la diferencia apuntada por Eisner (1998) entre investigación e indagación. Sin asumir del todo su carácter dicotómico, pues consideramos que hay procesos de indagación en una investigación formalizada que se vincula a un marco epistemológico y metodológico no narrativo (Hernández-Hernández, Domingo, Miño, Ornellas, 2013), pensamos que es útil en la medida en que enuncia dos modos de conocer y de saber.

La indagación, en tanto que apertura al mundo, no se conforma con la idea de investigación que impone unos límites dentro de los cuales se ha de inscribir de antemano el fenómeno con el que nos relacionamos y del cual tratamos de conocer algunos de sus relaciones. Esta disposición hacia la indagación hemos ido viendo que es clave en la investigación artística y en la IBA y pienso que también lo es en la investigación artística. 


\section{En resumen,... y para abrir el debate}

Lo que estamos planteando, lo que propongo reflexionar en esta mesa, es considerar, como hace Denis Atkinson, al referirse a la experiencia de aprendizaje real, que la relación entre artes e investigación "implica un movimiento dentro de un nuevo estado epistemológico, que define un problema de existencia, en contraste con el aprendizaje (la investigación) en sus normas y competencias cotidianas" (Atkinson, 2012: 9). Este movimiento es el que nosotros experimentamos en los cursos de IBA y en las investigaciones en el ámbito del postgrado en Artes y Educación, que nos supone una experiencia de participar en procesos de indagación que "producen un nuevo lineamiento entre pensamiento y acción" (Atkinson, 2012: 9) que permite que la investigación en artes contribuye a expandir el conocimiento y la experiencia que las artes generan y a trazar puentes con las ciencias sociales, de manera que deje de permanecer invisible y silenciado aquello que de otros modos no se puede mostrar y visibilizar.

\section{FUENTES REFERENCIALES}

Abakerli Baptista, Mariane (2014, enero). Fotografiar para contar otra historia: Una experiencia de formarse en grupo mediante procesos de indagación. $2^{\text {nd }}$ Conference on arts-based and artistic research: Critical reflections on the intersection between art and research. Granada: Universidad de Granada, 29 y 30 de enero.

Atkinson, Dennis (2012). Contemporary Art in Education: The New, Emancipation and Truth. The International Journal of Art \& Design Education, 31 (1), 5-18.

Calderón, Natalia (2014, enero). How can artistic research open up new spaces for knowledge? Notes from my research residency experience at Helsinki University of the Arts. $2^{\text {nd }}$ Conference on arts-based and artistic research: Critical reflections on the intersection between art and research. Granada: Universidad de Granada, 29 y 30 de enero.

Dorrego Carreira, Nando; Fendler, Rachel; Gaitán Villasclars, Julia; González Llopis, Paula; Gritane, Agita; Gutiérrez, Antonio; Hernández-Hernández, Fernando; Riera Retamero, Marina; Vaquero Latorre, Marina (2015, enero). The experience of being in the university in turbulent times: learning and doing arts-based research. $3^{\text {rd }}$ Conference on Arts-Based Research and Artistic Research. Faculty of Fine Arts, University of Porto, 28-30 January 2015

Eisner, Elliot (1998). The Enlightened Eye: Qualitative Inquiry and the Enhancement of Educational Practice. Upper Saddle River, NJ: Prentice Hall.

Fendler, Rachel; Hernández-Hernández, Fernando (2013). What Does Research Mean for Fine Arts Students? En: F. HernandezHernandez \& R. Fendler (Eds.), 1st Conference on arts-based and artistic research: Critical reflections on the intersection between art and research, pp. 227-232. Barcelona: University of Barcelona - Depsit Digital. http://hdl.handle.net/2445/45264

Hernández, F. (2006). Campos, temas y metodologías para la investigación relacionada con las artes. En AA.VV. Bases para un debate sobre investigación artística. (pp.9-50). Madrid: Ministerio de Educación y Ciencia

Hernández-Hernández, Fernando; Domingo, Maria; Miño, Raquel; Ornellas, Adriana (2013, septiembre). The ethnography of an ethnography. Studying learning experiences in and outside school with young people. European Conference for Educational Research ECER 2013. Estambul, $10-13$ de septiembre.

Hernández-Hernández, Fernando; Fendler, Rachel (2014). Explorar los límites: IBA puede ser muchas cosas, pero no cualquier cosa. $2^{\text {nd }}$ Conference on arts-based and artistic research: Critical reflections on the intersection between art and research. Granada: Universidad de Granada.

Onses, J., Fendler, R., Hernández-Hernández, F. (2012). Una investigación a/r/tográfica sobre la experiencia del silencio en las clases de la universidad. Invisibilidades 3, 29-40.

Siegesmund, Richard; Freedman, Kerry (2013). Images as Research: Creation and Interpretation of the Visual. En: HernandezHernandez \& R. Fendler (Eds.), 1st Conference on arts-based and artistic research: Critical reflections on the intersection between art and research. (pp.18-26). Barcelona: University of Barcelona - Deposit Digital. http://hdl.handle.net/2445/45264

Sullivan, Graeme (2011). The artist as researcher. New roles for new realities. En: J. Wesseling (ed.) See it again, say it again. The artist as researcher. (pp. 79-101). Amsterdan: Valiz. 